\title{
"Bath salts" intoxication: a new recreational drug that presents with a familiar toxidrome
}

\author{
Christine Hall, $\mathrm{MD}^{*}$; Christopher Heyd, $\mathrm{BSc}^{\dagger}$; Chris Butler ${ }^{\ddagger}$; Mark Yarema, $\mathrm{MD}^{\S}$
}

\section{ABSTRACT}

It is important for emergency physicians to be aware of new psychoactive agents being used as recreational drugs. "Bath salts," which include 3,4-methylenedioxypyrovalerone (MDPV), mephedrone, and methylone, are the newest recreational stimulants to appear in Canada. There are currently more than 12 synthetic cathinones marketed as bath salts and used with increasing frequency recreationally. Although these drugs are now illegal in Canada, they are widely available online. We present a case report and discuss bath salts intoxication and its anticipated sympathomimetic toxidrome, treatment strategies, and toxicologic analysis, Treatment should not rely on laboratory confirmation. Since the laboratory identification of such drugs varies by institution and toxicologic assay, physicians should not misconstrue a negative toxicology screen as evidence of no exposure to synthetic cathinones. Illicit bath salts represent an increasing public health concern that involves risk to the user, prehospital personnel, and health care providers.

\section{RÉSUMÉ}

Il est important que les urgentologues connaissent les nouvelles substances psychoactives utilisées comme drogues à usage récréatif. Les "sels de bain", qui contiennent de la 3,4-méthylènedioxypyrovalérone (MDPV), de la méphédrone et de la méthylone, sont les tout derniers stimulants à usage récréatif qui ont fait leur entrée au Canada. II existe actuellement plus d'une douzaine de cathinones synthétiques, qui sont vendus comme des sels de bain et qui sont de plus en plus utilisés à des fins récréatives. Bien que ces drogues soient maintenant illicites au Canada, on peut se les procurer facilement en ligne. II y aura dans I'article un exposé de cas, suivi d'une discussion sur l'intoxication aux "sels de bain", le toxidrome sympathomimétique prévisible, les stratégies de traitement et les analyses toxicologiques. Le traitement ne devrait pas reposer sur la confirmation des résultats des examens de laboratoire. Comme l'identification de ces drogues par les laboratoires varie d'un établissement à l'autre et selon les épreuves de dosage toxicologique, les médecins ne devraient pas interpréter à tort un test de dépistage toxicologique négatif comme un signe d'absence d'exposition à des cathinones synthétiques. Les sels de bain illicites posent un problème de santé publique, qui prend de I'ampleur et qui présente des risques pour l'utilisateur luimême, pour le personnel préhospitalier et pour les fournisseurs de soins de santé.

Keywords: bath salts, emergency, 3,4-methylenedioxypyrovalerone (MDPV), risk, toxicology, toxidrome, treatment

It is important for emergency physicians to be aware of new psychoactive agents being used as recreational drugs. "Bath salts," which include 3,4-methylenedioxypyrovalerone (MDPV), mephedrone, and methylone, are the newest recreational stimulants to appear in Canada. There are currently more than 12 synthetic cathinones marketed as bath salts and used with increasing frequency recreationally. Although these drugs are now illegal in Canada, they are widely available online. We present a case report and discuss bath salts intoxication and its anticipated sympathomimetic toxidrome, treatment strategies, and toxicologic analysis.

\section{CASE REPORT}

\section{Prehospital events}

Parents of a 21-year-old man called 911 because their son was having a "psychotic episode" after sniffing

From the *Vancouver Island Health Authority, Victoria, BC; Department of Emergency Medicine, University of British Columbia, Vancouver, BC; and the Faculty of Medicine, Department of Community Health Sciences, University of Calgary, Calgary, AB; †lsland Medical Program, Faculty of Medicine, University of British Columbia, Vancouver, BC; $¥$ Calgary Police Service, Calgary, AB; §Poison and Drug Information Service, Alberta Health Services; the Division of Emergency Medicine, University of Calgary, Calgary, AB.

Correspondence to: Dr. Christine Hall, Department of Emergency Medicine, University of British Columbia, Royal Jubilee Hospital, 1952 Bay Street, Victoria, BC V8R 1J8; Christine.Hall@viha.ca.

This article has been peer reviewed. 
"bath salts." At the same time, the man himself called 911 and stated that his parents had been murdered. He had not slept for 48 hours and had spent the night opening and closing doors and turning lights on and off.

On police arrival, the man stated that his parents had been "killed and replaced" and continued to dial 911 despite the presence of police. Verbal interventions by police were disregarded, and physical contact resulted in a violent struggle. The man was described as having "superhuman strength" and was seemingly impervious to pain. He was perspiring heavily and making growling sounds and appeared to be hallucinating. Additional police officers and advanced life support paramedics were deployed, and seven police officers were required to gain physical control.

The paramedics immediately administered $10 \mathrm{mg}$ of midazolam intramuscularly. The patient was restrained in a supine position with handcuffs in front of his body and transported to the emergency department (ED).

\section{Initial ED presentation}

On ED arrival, the patient's vital signs were as follows: heart rate 117 beats/min; blood pressure 128/52 $\mathrm{mm} \mathrm{Hg}$; respiratory rate 18 breaths $/ \mathrm{min}$; temperature $36.6^{\circ} \mathrm{C}$ $\left(97.8^{\circ} \mathrm{F}\right)$; and oxygen saturation $100 \%$ on $4 \mathrm{~L} / \mathrm{min}$ of oxygen by nasal prongs. A physical examination revealed no evidence of trauma. An electrocardiogram showed sinus tachycardia with normal intervals and no QT prolongation, ischemic features, or evidence of left ventricular hypertrophy.

Table 1 provides results for noteworthy initial laboratory investigations. Serum creatine kinase was elevated, peaked at 2,818 IU/L 12 hours later, and remained elevated at $1,750 \mathrm{U} / \mathrm{L} 24$ hours after presentation. The complete blood count normalized within 12 hours, and renal function and potassium remained normal. Venous blood gas determination 30 minutes after ED arrival revealed $\mathrm{pH}$ of 7.35 , carbon dioxide tension $\left(\mathrm{pCO}_{2}\right)$ of $37 \mathrm{~mm} \mathrm{Hg}, \mathrm{HCO}_{3}{ }^{-}$ of $20 \mathrm{~mm} \mathrm{Hg}$, and lactate of $3.8 \mathrm{mmol} / \mathrm{L}$ (normal < $2 \mathrm{mmol} / \mathrm{L}$ ). The venous lactate normalized after sedation and intravenous (IV) hydration with normal saline.

\section{Toxicology testing}

Ethanol level was $<2 \mathrm{mmol} / \mathrm{L}$. The initial urine toxicologic screen was negative for cocaine, amphetamines, cannabinoids, opiates, and barbiturates but positive for benzodiazepines.

Comprehensive urine drug screening via gas chromatography/mass spectrometry (GC/MS) completed 7 hours after the patient's arrival was positive for 3,4methylenedioxypyrovalerone (MDPV) and revealed chlorpheniramine (an antihistamine) and trazodone, which the patient had not been prescribed.

\section{Past medical history}

Past history, obtained subsequent to his initial presentation, revealed that the patient had been sniffing bath salts habitually for 1 year and had been using them continuously for 7 to 10 days. He admitted to also using benzylpiperazine, a stimulant drug with euphoric properties. When bath salts became illegal in North America, he began ordering them from China. He had been in hospital on five previous occasions for bizarre behaviour and twice held under a Mental Health Certificate with drug-induced psychosis. When abstinent from drugs, he had no psychotic features.

\begin{tabular}{lccc}
\hline Table 1. Initial laboratory investigations & & & \\
\hline Test & Value & Normal range & Reference units (SI) \\
\hline White blood cell count & $17.2^{*}$ & $4-11 \times 10^{9}$ & $\times 10^{9} / \mathrm{L}$ \\
Neutrophils & $14.5^{*}$ & $2-8$ & $\times 10^{9} / \mathrm{l}$ \\
Potassium & 4.0 & $3.3-5.1$ & $\mathrm{mmol} / \mathrm{L}$ \\
Serum CO & $21-31$ & $\mathrm{mmol} / \mathrm{L}$ \\
Creatinine & $20^{*}$ & $50-120$ & $\mu \mathrm{mol} / \mathrm{L}$ \\
Anion gap & 85 & $3-11$ & $\mathrm{mmol} / \mathrm{L}$ \\
Osmolality & $14^{*}$ & $280-300$ & $\mathrm{mmol} / \mathrm{kg}$ \\
Creatine kinase & 289 & $0-195$ & $\mathrm{IU} / \mathrm{L}$ \\
\hline *Abnormal. & $464^{*}$ & & \\
\hline
\end{tabular}




\section{Course in the ED}

The patient remained paranoid and physically restrained because of intermittent agitation and aggression. Benzodiazepines were administered (three doses of midazolam $5 \mathrm{mg}$ IV and a total of $14 \mathrm{mg}$ of lorazepam IV). Three doses of haloperidol $1 \mathrm{mg}$ IV were also given. Because of ongoing severe agitation, a continuous IV propofol infusion was commenced and continued for 8 hours.

\section{Course in hospital}

Twenty-four hours after his ED arrival, the patient was transferred to the psychiatry in-patient service. He was discharged 3 days later with a diagnosis of substanceinduced psychosis. He had no ongoing psychiatric symptoms at discharge.

\section{DISCUSSION}

Compounds, including MDPV, mephedrone, and methylone, are colloquially known as "bath salts" and are the newest recreational stimulants to appear in Canada. There are more than 12 synthetic cathinones, marketed as bath salts and increasingly used recreationally. Bath salts are labeled by illicit distributors as beauty products, plant food, or pond cleaner. The original beauty product label led to the wide use of the bath salts moniker. ${ }^{1,2}$ Distributors have skirted regulatory bodies by declaring bath salts "not for human consumption." Bath salts intended for substance abuse are sold in "headshops" or via Internetbased companies that ship internationally. Packaging carries names such as Vanilla Sky, Purple Wave, and Red Dove. Users pay up to $\$ 75 \mathrm{CAD}$ for 20 to $30 \mathrm{~g}$. These agents are vastly different from products intended for actual bathing or gardening sold by large-scale retailers. ${ }^{1-4}$ Bath salts began to appear on the streets in Europe in 2007 and the United States in 2008 and are now increasingly distributed in Canada., 2,5 The first reported illicit use in Canada was in 2012 in Nova Scotia, and bath salts have now been documented in most provinces. ${ }^{5,6}$

Bath salts can be orally ingested, sniffed, snorted, smoked, or injected. The desired effects of euphoria, increased energy, expanded consciousness, and increased libido begin rapidly, typically last for 3 to 4 hours, and are associated with considerable adverse effects. ${ }^{1,4,7-9}$ The duration of action is typically 2 hours or longer, although the actual half-life is difficult to ascertain due to a lack of pharmacokinetic evidence, the frequent presence of coingestants, and the possibility of undetermined contaminants. ${ }^{3}$ Use is often continuous, with another dose taken as soon as the euphoria wanes. It is not uncommon for users to maintain a high for several days, resulting in rapid dose escalation as tolerance develops. Users and observers of bath salts have reported psychotic features with involuntary psychomotor activity, compulsive behaviour, and disturbing hallucinations. Severe selfmutilation has been reported. Underlying psychiatric disease or a history of polysubstance use can further complicate the presentation. Bath salts intoxication has been linked to significant morbidity and mortality, and the effects of intoxication present an obvious safety risk for emergency medical services (EMS) providers and law enforcement personnel. . $3,10^{3}$

The most common synthetic cathinone found in bath salts in North America is MDPV. The closely related compounds mephedrone (4-methylmethcathinone) and methylone have also been reported but are more frequently seen in Europe., ${ }^{2,411}$ Bath salts became illegal in Canada in September 2012. ${ }^{6}$

\section{MDPV's mechanism of action}

Bath salts are often a mixture of centrally acting synthetic cathinones combined with contaminants that may include traces of prescription drugs ${ }^{1-3,7,8,12}$ (Table 2). Many users of bath salts attempt to mitigate any untoward psychotic features by coingesting known "downers" such as marijuana, heroin, narcotics, and major tranquilizers. ${ }^{12,13}$

Table 2. Reported constituents in bath salts and coingestants in bath salts intoxication

Reported constituents in bath salts

MDPV (3,4-methylenedioxypyrovalerone)

Mephedrone

Methylone

Caffeine

Lidocaine

Trimethoprim

Unidentifiable compounds

Reported coingestants in bath salts intoxication

Marijuana, opiates, benzodiazepines, cocaine, amphetamines

Ethanol, methadone, zolpidem, buprenorphine, tramadol,

methylphenidate, chlorpheniramine, trazodone 
MDPV, like other synthetic cathinones, has stimulant effects similar to those of cocaine and amphetamines. Because it is lipophilic, it crosses the blood-brain barrier, where it acts as a monoamine reuptake inhibitor and induces the release of dopamine, norepinephrine, and serotonin. ${ }^{1,712}$ MDPV results in dopaminergic stimulation of the corticomesolimbic pathways, including the reward centre in the nucleus accumbens. Dopaminergic stimulation is thought to underlie the dependence, tolerance, and withdrawal syndrome. Overstimulation of $\mathrm{D}_{2}$ receptors within the limbic system has been linked with hallucinations. It has been estimated that the central dopaminergic effect of MDPV is up to nine times greater than that of cocaine. ${ }^{1,7,9}$

The norepinephrine effects of MDPV are both central and peripheral, resulting in alertness, arousal, decreased fatigue, and insensitivity to pain. Stimulation of $\alpha_{1}$ and $\beta_{1}$ receptors increases heart rate and causes hypertension. ${ }^{1,3}$

The serotoninergic activities of bath salts cause euphoria, altered perception, heightened awareness, hallucinations, and reduced appetite. ${ }^{12}$ Alterations in perception combined with central analgesia may be responsible for the extensive self-mutilation and tolerance to pain-mediated control techniques seen in individuals with bath salts intoxication. ${ }^{1,9,11}$

\section{Clinical presentation}

Table 3 provides common signs and symptoms seen in bath salts intoxication. Bath salts typically present with a sympathomimetic toxidrome with altered consciousness that ranges from agitation to frank psychosis. Findings include tachycardia, hypertension, dysrhythmias, diaphoresis, mydriasis, tremor, and muscle weakness. ${ }^{1,2,4}$ Chest pain, myocardial infarction, stroke, coma, and death have also been reported., ${ }^{3,10}$ Behavioural changes include psychomotor activation, agitation, aggression, amnesia, and insomnia. Paranoia, delusions, and hallucinations have been reported in up to $90 \%$ of cases., ${ }^{4,14-17}$ Bath salts toxicity can be difficult to differentiate from cocaine or amphetamine use, although bath salts toxicity may result in more severe psychosis and include selfinjurious behaviour. A recent case of serotonin syndrome related to MDPV use suggests a larger effect on the reuptake of serotonin than initially thought. ${ }^{12}$ Serotonin syndrome signs, such as myoclonus, diaphoresis, tremor, hyperreflexia, and hyperthermia, have all been reported

\begin{tabular}{l} 
Table 3. Common signs and symptoms seen in bath salts \\
intoxication \\
\hline Sympathetic \\
Tachycardia \\
Hypertension \\
Chest pain \\
Mydriasis \\
Psychiatric \\
Agitation \\
Combative and violent behaviour \\
Hallucinations \\
Delusions \\
Paranoia \\
Neurologic \\
Confusion \\
Seizure/tremor \\
Drowsiness \\
Myoclonus \\
Blurred vision
\end{tabular}

in confirmed cases of MDPV use. ${ }^{1,3,12}$ Hyperthermia has been documented and seems to relate to central dysregulation of dopamine and noradrenaline in the hypothalamus. ${ }^{710}$ However, it has also been suggested that peripheral mechanisms are responsible, including an MDMA-like (3,4-methylenedioxy- $N$-methylamphetamine or "Ecstasy") uncoupling of cellular respiratory proteins and noradrenaline-mediated vasoconstriction preventing superficial cooling. ${ }^{1,7,9}$

The presentation of a mixed toxidrome is likely due to the user's coingestion of "downers" such as major tranquilizers in an attempt to mitigate the psychomotor responses to bath salts. ${ }^{13}$ In our case, GC/MS assessment revealed coingestion of an antihistamine and trazodone. For this reason, a wide range of coingestants must be considered, even as treatment is unfolding. ${ }^{14,16,18-20}$

\section{Treatment}

There are currently no evidence-based guidelines for treatment of bath salts intoxication; however, it is reasonable to use guidelines for sympathomimetic toxidromes and excited delirium, ${ }^{1,2,4,18-20}$ recognizing that serotonin syndrome may also be encountered. ${ }^{12}$ When an undifferentiated patient with a sympathomimetic toxidrome is seen, clinicians should consider the possibility of bath salts intoxication.

Bath salts users generally present to the ED after a police response for bizarre, violent, or dangerous 
behaviour. Dispatch of adequate numbers of EMS providers and law enforcement personnel is prudent. ${ }^{18-20}$ The goal of initial intervention is rapid de-escalation of agitation and sympathetic system stimulation, as with any sympathomimetic toxidrome. Physical restraint is important to protect the safety of health care providers and should be augmented with chemical restraint as rapidly as possible. Benzodiazepines are the mainstay of initial treatment, along with consideration of dissociative agents and propofol infusion. ${ }^{1,3,4,13}$

Similar to cocaine toxicity, the administration of $\beta$ blockers or similar agents to control hypertension is contraindicated as this may result in complications from unopposed $\alpha$-adrenergic stimulation. ${ }^{21}$ Continuous electrocardiographic monitoring, coupled with management of hyperthermia and dehydration when indicated, should be started in the field. Hospital evaluation should include the assessment and treatment of rhabdomyolysis, acidosis, dehydration, and electrolyte abnormalities.,10,11 Physicians should be vigilant for the possible development of serotonin syndrome. ${ }^{12}$

\section{Toxicologic assessment}

Initiation of treatment should not rely on laboratory confirmation. Standard urine drug toxicologic screens cannot detect bath salts. Specialized analysis for the presence of the most common cathinones using GC/ MS is required if a definitive diagnosis is desired. ${ }^{1,3,4}$ Quantitation of serum MDPV levels is not routinely performed in Canada. Requests for such levels may require involvement of a forensic laboratory. ${ }^{3}$

The difficulty in the toxicologic assay of synthetic cathinones rests with establishment of base levels for cutoff. If levels present in the urine are below the base level of detection for an assay, the screen will be reported as negative. Changes in chemical structures resulting from manufacturers' efforts to skirt legal limitations, as well as the presence of multiple compounds with varying side chains in the same drug portion, may confound qualitative testing. $2,5,6$ The clinical response to the bath salts may last well beyond MDPV's measurable half-life, leading to an impressive clinical picture in the setting of a negative toxicologic analysis. ${ }^{4}$ Suspicion of bath salts intoxication is sufficient to initiate treatment, and the importance of specific findings on assay are difficult to interpret because there is wide variation in the clinical response to MDPV.

\section{Prognosis}

A wide range of outcomes from bath salts toxicity have been documented. Many patients have recovered with no long-term sequelae despite severe acute medical effects, including renal failure. . $^{1,8,10}$ However, there have been a number of deaths following MDPV consumption despite aggressive medical treatment., ${ }^{3,10,11}$

\section{SUMMARY AND CONCLUSIONS}

Bath salts represent new and dangerous drugs of abuse, involving intoxication that presents as a sympathomimetic toxidrome. The duration and clinical presentation of bath salts toxicity are frequently complicated by continuous dosing users, the self-administration of depressive agents, and the contamination of the compounds with prescription drugs and other contaminants. Toxicologic analysis is difficult, and a negative assay does not necessarily indicate nonexposure. Although bath salts are now illegal in Canada, these agents are widely available online and have become an increasing public health concern that involves risk to the user, prehospital personnel, and health care providers.

Competing interests: None declared.

\section{REFERENCES}

1. Coppola M, Mondola R. 3,4-Methylenedioxypyrovalerone (MDPV): chemistry, pharmacology and toxicology of a new designer drug of abuse marketed online. Toxicol Lett 2012; 208:12-5, doi:10.1016/j.toxlet.2011.10.002.

2. Emergency department visits after use of a drug sold as "bath salts"-Michigan, November 13, 2010-March 31, 2011. MMWR Morb Mortal Wkly Rep 2011;60:624-7.

3. Murray BL, Murphy CM, Beuhler MC. Death following recreational use of designer drug "bath salts" containing 3,4methylenedioxypyrovalerone (MDPV). 7 Med Toxicol 2012;8: 69-75, doi:10.1007/s13181-011-0196-9.

4. Spiller HA, Ryan ML, Weston RG, Jansen J. Clinical experience with and analytical confirmation of "bath salts" and "legal highs" (synthetic cathinones) in the United States. Clin Toxicol (Phila) 2011;49:499-505, doi:10.3109/15563650. 2011.590812.

5. Black M. What are "bath salts"? A look at Canada's newest illegal drug. CBC News. 2012. Available at: http://www.cbc.ca/ news/canada/story/2012/06/25/f-faq-bath-salts.html (accessed July 15, 2013).

6. Health Canada. Schedule I Controlled Drugs and Substances Act. 2012. Available at: www.hc-sc.gc.ca (accessed November 12, 2012). 
7. Prosser JM, Nelson LS. The toxicology of bath salts: a review of synthetic cathinones. 7 Med Toxicol 2012;8:33-42, doi:10.1007/s13181-011-0193-z.

8. Ross EA, Reisfield GM, Watson MC, et al. Psychoactive "bath salts" intoxication with methylenedioxypyrovalerone. Am 7 Med 2012;125:854-8, doi:10.1016/j.amjmed.2012. 02.019. [Epub 2012 Jun 9]

9. Kelly JP. Cathinone derivatives: a review of their chemistry, pharmacology and toxicology. Drug Test Anal 2011;3:43953, doi:10.1002/dta.313.

10. Borek HA, Holstege CP. Hyperthermia and multiorgan failure after abuse of "bath salts" containing 3,4-methylenedioxypyrovalerone. Ann Emerg Med 2012;60:103-5, doi:10. 1016/j.annemergmed.2012.01.005.

11. Kasick DP, McKnight CA, Klisovic E. "Bath salt" ingestion leading to severe intoxication delirium: two cases and a brief review of the emergence of mephedrone use. Am 7 Drug Alcohol Abuse 2012;38:176-80, doi:10.3109/00952990.2011. 643999.

12. Mugele J, Nanagas KA, Tormoehlen LM. Serotonin syndrome associated with MDPV use: a case report. Ann Emerg Med 2012;60:100-2, doi:10.1016/j.annemergmed. 2011.11.033.

13. Kriikku P, Wilhelm L, Schwarz O, Rintatalo J. New designer drug of abuse: 3,4-methylenedioxypyrovalerone (MDPV). Findings from apprehended drivers in Finland. Forensic Sci Int 2011;210:195-200, doi:10.1016/i.forsciint.2011.03.015.
14. Penders TM, Gestring RE, Vilensky DA. Intoxication delirium following use of synthetic cathinone derivatives. Am 7 Drug Alcohol Abuse 2012;38:616-7, doi:10.3109/ 00952990.2012.694535. [Epub 2012 Jul 11]

15. Penders TM. How to recognize a patient who's high on "bath salts." F Fam Pract 2012;61:210-2.

16. Penders TM, Gestring R. Hallucinatory delirium following use of MDPV: "bath salts." Gen Hosp Psychiatry 2011;33:5256, doi:10.1016/j.genhosppsych.2011.05.014.

17. Antonowicz JL, Metzger AK, Ramanujam SL. Paranoid psychosis induced by consumption of methylenedioxypyrovalerone: two cases. Gen Hosp Psychiatry 2011;33:640-6.

18. Vilke GM, Bozeman WP, Dawes DM, et al. Excited delirium syndrome (ExDS): treatment options and considerations. 7 Forensic Leg Med 2012;19:117-21, doi:10.1016/j.jflm.2011.12.009.

19. Vilke GM, Payne-James J, Karch SB. Excited delirium syndrome (ExDS): redefining an old diagnosis. 7 Forensic Leg Med 2012;19:7-11, doi:10.1016/j.jflm.2011.10.006.

20. Vilke GM, Debard ML, Chan TC, et al. Excited delirium syndrome (ExDS): defining based on a review of the literature. $\mathcal{F}$ Emerg Med 2012;43:897-905, doi:10.1016/ j.jemermed.2011.02.017. [Epub 2011 Mar 25]

21. Ramoska E, Sacchetti AD. Propranolol-induced hypertension in treatment of cocaine intoxication. Ann Emerg Med 1985;14:1112-3, doi:10.1016/S0196-0644(85)80934-3. 